\title{
A comparative analysis of the voting behavior of constituents and their representatives for public debts
}

\author{
Reiner Eichenberger • David Stadelmann • \\ Marco Portmann
}

Published online: 25 May 2012

(C) Springer Science + Business Media, LLC 2012

\begin{abstract}
We explore the quality of political representation of constituents' preferences for budgetary decisions within a quasi-experimental setting. In the Swiss referendum process, constituents reveal their preferences for budgetary proposals which are either expected to increase or decrease public debts. We match individual politicians' voting behavior on debt increasing and debt reducing legislative proposals with eight real referendum decisions on exactly the same issues from 2008 to 2011. Thereby, we directly explore deviations of politicians from constituents' preferences with respect to budgetary policies.
\end{abstract}

Keywords Fiscal preferences $\cdot$ Political representation · Debts

JEL Classification D7 $\cdot$ H7

\section{Introduction}

Government debt accumulation is often explained by the interaction of competing interest groups and political parties (Alesina and Drazen 1991; Drazen and Grilli 1993; Brennan 2011). Interest groups tend to lobby for higher subsidies and

R. Eichenberger $\cdot$ D. Stadelmann $(\bowtie) \cdot$ M. Portmann

Department of Economics, University of Fribourg, Bd. de Pérolles 90, 1700 Fribourg, Switzerland e-mail: david.stadelmann@unifr.ch

R. Eichenberger

e-mail: reiner.eichenberger@unifr.ch

M. Portmann

e-mail: marco.portmann@unifr.ch

R. Eichenberger - D. Stadelmann

CREMA-Center for Research in Economics, Management and the Arts, Gellertstrasse 18, 4052 Basel, Switzerland 
preferential tax treatment. However, representatives are not only dependent on interest groups but also on the constituency which determines their reelection. As constituents have preferences for increasing or decreasing public debts, the actual development of debts may also reflect the representation of citizens' preferences.

Large deviations in parliamentary decisions from citizens' preferences have been reported in the literature (see Stratmann 1995; Gerber and Lewis 2004; Stadelmann et al. 2012a, b). Such deviations may depend on factors such as electoral systems and the personal interests of politicians but the respective literature is still sparse. This article aims to explore the deviation of politicians' decisions from constituents' preferences with respect to budgetary policies with a particular focus on representation of preferences for public debts.

Switzerland offers a unique quasi-experimental setting for a comparative analysis of preferences and political budgetary decisions which either increase or decrease public debts. Like other democratic countries, members of the Swiss parliament vote on legal and constitutional amendments which affect public debts. But in contrast to other countries, all changes to the law may be subject to a 'facultative referendum', i.e. citizens can demand a popular vote on the respective changes before they are enacted. Moreover, all constitutional amendments have to pass a popular vote. Finally, a group of citizens can also start an initiative and demand a specific constitutional amendment; members of parliament then express their opinion on amendments proposed by these initiatives.

Constituents reveal their preferences for policy outcomes in referenda by ranking law proposals against the status quo (see Schneider et al. 1981; Frey 1994; Besley and Coate 2008; Brunner et al. 2011; Portmann et al. 2012). We match the results of eight budgetary decisions from 2008 to 2011 with the individual voting data for Swiss members of parliament on the identically worded decisions in parliament. Thus, we directly observe whether the members of parliament from both chambers have voted in line with the majority of their constituents in decisions affecting public debts. We offer a first explorative analysis drawing on the Swiss setting which constitutes an ideal field to study the importance that political representatives place on their constituents' preferences regarding public debts.

In order to evaluate the gap between politicians and constituents with respect to public debts, it is necessary to assess all referenda to determine whether they affect the fiscal balance. Almost any political decision entails certain fiscal consequences or facilitates the introduction of new laws which in turn have fiscal consequences. Our identification of budgetary issues increasing or decreasing debts is based on the official documentation, i.e. on the official booklets sent to voters several weeks before the referendum takes place. Consequently, we classify the referenda according to the official information voters receive and on which they base their decisions.

Our study benefits from an important advantage. Because our research focuses on differences within a single country, it avoids problems common to cross-country research. When analyzing political decisions and preferences across countries, specific norms, rules, political patterns, history, culture and institutional contexts 
should be taken into account. In our case, the sub-national electoral districts provide a broad empirical field within a common framework.

The remainder of this paper is structured as follows. Section 2 briefly reviews the literature on the representation of voter preferences and referenda. Section 3 presents a short overview of the Swiss political system, highlights the role of referenda and details how we match representatives' behavior in parliament with citizens' opinions in referenda. Explorative results for all members of parliament from both chambers are presented in Section 4. Finally, Section 5 offers some concluding remarks.

\section{Literature}

When electoral competition works along a single policy dimension, candidates represent the median voters' position according to Downs (1957). This appealing theoretical prediction of convergence contrasts with the literature on legislative shirking and empirical studies on representation which show that systematic deviations from voters' interests occur (see Kau and Rubin 1978, 1979; Lott and Davis 1992; Stratmann 1995; Bender and Lott 1996; Gerber and Lewis 2004; Stadelmann et al. 2012a, b). A critical assessment of spatial voting models and their alternatives is offered by Grofman (2004). ${ }^{1}$

Legislators seem to react to other stimuli than voters' preferences. In particular, interest groups and campaign contributions may influence their decisions (see, e.g., Denzau and Munger 1986; Stratmann 1992). Moreover, political parties and their respective ideologies are also likely to matter (see, e.g., Alesina and Rosenthal 1989; Levitt 1996; Carey 2007; Stadelmann et al. 2012b).

The measurement of voters' preferences and their match with legislators' behavior is central to the empirical literature on political representation. The major difficulty lies in determining congruence levels between voters and politicians (see Golder and Stramski 2010 and Matsusaka 2010 for recent discussions). Voters' views are represented by politicians if the latter cast the same vote on a legislative issue that voters would have if they had been in a position to do so. Since such a direct measure for congruence is usually not available, congruence between politicians and voters is usually measured by surveys or "ideology scores" such as the ADA scores in the United States (see, e.g., Kenny and Lotfinia 2005; López and Ramírez 2008). To obtain proxies for district majority preferences, legislators' scores are usually regressed on districts' characteristics and the fitted ADA scores are considered to represent the district's interests, whereas the residuals exhibit the politician's divergence from his/her constituency. Such measures based on constituency characteristics have been criticized as inappropriate measures of legislative preferences by Krehbiel (1993), among others. Matsusaka (2010) highlights the limitations of different scores as they do not directly match voters' choices with politicians' behavior.

\footnotetext{
${ }_{1}^{1}$ Dow (2001) and again Grofman (2004) provide excellent reviews of the literature on party competition.
} 
A small number authors discuss the effects of referenda on the political process, citizens' representation and citizens' wellbeing (see, e.g., Frey 1994; Matsusaka 1995; Gerber 1996; Feld and Matsusaka 2003). Only a few scholars consider roll call votes or referenda outcomes as measures for constituents' representation (see Hersch and McDougall 1988; Garrett 1999). More recently, Gerber and Lewis (2004) draw on a dataset from California and compare legislators' roll call votes on a unidimensional NOMINATE scale to districts' median voter preferences estimated from referenda.

Our approach overcomes problems of measures for legislators' and voters' positions constructed from ideology scores or surveys. We directly compare representatives' roll call votes and citizens' preferences revealed in referenda which either increase or decrease debts. The use of such a direct measure of congruence has recently also been suggested by Matsusaka (2010) for the United States. Brunner et al. (2011) apply it to Californian data and advocate that results may be generalized to other U.S. states. ${ }^{2}$

With respect to preferences for expenditure on local public goods, Ågren et al. (2007) investigate survey responses from Swedish citizens and politicians. They find that politicians have higher preferences for higher expenditures then citizens. However, we are not aware of any contributions in the literature which use revealed preferences in referenda and roll call votes in parliament in order to explore congruence between politicians and constituents with respect to legislative proposals influencing public debts.

As argued by Eusepi and Wagner (2012), parliamentary assemblies do not necessarily trade on their own account. In their dealings they may deviate from voters' preference for debt because they may follow the notion of a "monopolistic republic" or because they may lack accurate information. Therefore, it is crucial to know whether they act in the interest of voters or not.

\section{Measuring voters' preferences and legislators' decisions}

\subsection{Parliamentary decisions and referenda}

Switzerland's federal constitution, dating back to 1848, established a bicameral parliament called the Federal Assembly. The Swiss constitutional setting has basically been modeled according to the United States. The parliament comprises two houses, the National Council ("Nationalrat" in German; comparable to the U.S. House of Representatives) and the Council of States ("Ständerat" in German; comparable to the U.S. Senate). Members of both councils are elected in the same 26 districts (Swiss cantons) and serve four-year terms.

The Swiss National Council has 200 seats. Its members are elected under a system of proportional representation. The number of representatives for each canton is proportional to its population size. Population size and, thus, the number of seats differ widely between cantons. For example, six cantons have only one

\footnotetext{
${ }^{2}$ In thematically completely different contributions we also discuss how this congruence measure generalizes (see Stadelmann et al. 2012a, b).
} 
representative in the National Council: Appenzell i.R., Appenzell a.R., Glarus, Nidwalden, Obwalden and Uri. Thirteen electoral districts have between one and five members of parliament, while the remaining cantons have more than five members of parliament.

The Swiss Council of States has 46 seats. For historical reasons, there are 20 "full cantons" and 6 "half cantons" making a total of 23 so called "Stände". There is no important difference between full and half cantons except that the latter have only one member in the Council of States. ${ }^{3}$ The six half cantons are Basel-Stadt and Basel-Land, Obwalden and Nidwalden, along with Appenzell a.R. and Appenzell i.R. The councilors are elected by majority rule. ${ }^{4}$ Thus, we are able to analyze representation of constituents' preferences for different electoral systems, a majority system for the Council of States and a proportional system for the National Council.

Parliamentary committees are concerned with elaborating policy proposals in different areas such as foreign affairs, social security, health, etc. These committees formulate proposals for new laws and changes to existing laws. A proposal is adopted as a new law or as a constitutional amendment, if the majorities of both the National Council and the Council of States approve it.

However, proposals adopted by parliament do not necessarily turn into law. Switzerland features a system of direct democracy where referenda may be held; this is a system similar to that in over half of the states in the United States. There are three types of popular votes (see Stadelmann et al. (2012b) for additional details and descriptions):

1. Citizens can challenge a law that has been passed by parliament by means of a facultative referendum which requires collecting at least 50,000 signatures within 100 days. Out of approximately 4.9 million registered voters, 50,000 signatures represent less than $1 \%$ of the population which is all that is required to demand a referendum. The proposed law or law change is rejected if a simple majority of the voters decides against it.

2. Parliamentary proposals to change the constitution are subject to a mandatory referendum. The constitutional change has to be confirmed by a "double majority". This means that in addition to a majority of all voters in the country, voter majorities in "eleven and a half cantons" (a majority of the "Stände") have to accept the constitutional change too.

3. Citizens may propose a constitutional amendment and demand a referendum on their proposal by collecting at least 100,000 signatures (the aforementioned "initiative"). The signatures have to be collected within 18 months. An

\footnotetext{
${ }^{3}$ The reason for the existence of "half cantons" is purely historical: When a canton separated into two parts, be it because of religious or socio-economic tensions, the new parts were counted only as half cantons, i.e. the new parts did not get more seats in the Council of States than the old unit, which provides the citizens of each canton with incentives for not being too eager to separate. An exception to this rule was made in 1979 when the old Canton of Berne separated into the full Canton of Jura and the new full Canton of Berne, which remained the second largest canton.

${ }^{4}$ The only exception is the Canton of Jura where the two members are elected by proportional voting. Omitting them does not change the results. Citizens of the Canton of Neuchâtel voted in favor of changing the electoral system from majority voting to proportional representation on September 26, 2011; all parliamentary decisions in our sample took place before this date.
} 
initiative formulates the precise wording of the new amendment as it has to be added to the constitution. Members of parliament are required to hold a vote on the text of an initiative. Their vote serves as a parliamentary recommendation to voters. Parliament and the government can neither change the wording of an initiative nor can they refuse an initiative, unless it violates formal rules. However, they can work out a counter-proposal to the initiative which is presented to the voters at the same time as the initiative in a referendum. Usually, a counter-proposal is designed to be a compromise between the current status quo and the demands stipulated in the initiative.

We analyze a sample of eight referenda which affect public debts from 2007 to 2011. For this period of time, data on individual roll call votes for the National Council and the Council of States are available. We identify referenda which affect public debts by referring to the official information given to Swiss voters before a referendum. Before the referendum takes place, voters receive an official booklet by post. This booklet provides information on the referendum issue in a neutral form and includes the exact text of the legislative paragraphs to be modified or introduced in the law or the constitution. For facultative referenda and initiatives, the counter committees which have collected signatures may point out their arguments and parliament usually points out its position too. Thus, citizens get the full view of not only the issue at stake, but also the different perspectives on it.

The official booklet allows the identification of referenda which increase or reduce public debts. We identify potentially debt increasing or reducing referenda by analyzing whether the booklet points out to voters any increases or decreases in expenditure or decreases or increases in taxation, i.e. affects the budget in a clear direction. Clearly, any law change may affect the budget even though it is not stated directly. ${ }^{5}$ However, as we are interested in referenda results with respect to politicians' decisions, the most straightforward method is to focus on the officially and easily available information which voters have when they decide.

Table 1 presents some descriptive statistics regarding the type of referenda analyzed.

Out of the eight budgetary referenda, four are debt increasing and four are debt reducing. Mandatory and facultative referenda make up half of the analyzed cases, the other half are initiatives. Out of the total of eight referenda, $50 \%$ have been adopted. The average cantonal share of acceptance amounts to $39.9 \%$. Thus, some referenda have also been clearly rejected which introduces an important variation in the referenda results which we can exploit for our empirical analysis.

\footnotetext{
5 Consider for example, the initiative of November 28, 2010 to facilitate the deportation of criminal foreigners. While the initiative may increase enforcement costs it may reduce total costs as foreigners do not spend time in Swiss prisons. In such cases, it would be most difficult to estimate the budgetary consequences and impossible to get a consensus about these estimates. Therefore, the official booklet does not explicitly state any budgetary consequences and therefore we do not classify the referendum as a potentially debt increasing or debt reducing one.
} 
Table 1 Debt increasing and debt reducing referenda from 2008 to 2011

All referenda

Number of debt increasing referenda 4

Number of debt reducing referendy

Number of facultative or mandatory referenda

Number of initiatives

4

Share of accepted referenda

$50 \%$

Cantons voting "yes" on average

$39.9 \%$

\subsection{Matching legislators' decisions with constituents' preferences}

Referenda results determine policy outcomes and at the same time reveal the preferences of citizens for these outcomes. Referenda permit voters to rank the expected policy outcomes of proposed laws against the status quo as pointed out by Schneider et al. (1981). Referenda produce dichotomous results which indicate what a majority prefers and consequently, what the median constituent prefers. Moreover, decisions in referenda are capable of capturing much broader issues than financial streams and it is not necessary to rely on experts' judgments or surveys concerning the utility implications for the majority.

Referenda data can be matched with voting data from members of parliament. The wording of the referendum text presented to the voter is the same as the one which members of parliament voted upon. This fact makes Switzerland an ideal field to study the relationship between constituents and politicians. According to Krehbiel (1993), roll call votes are most proximate to the adoption of governmental policies. The vote in the Swiss parliament is binding and policy-relevant which starkly contrasts with the electoral platforms of political parties and individual candidates. The same applies to referendum decisions which are implemented right after the popular vote. Thus, referenda have a much more direct influence on policy than voter surveys.

All roll calls in the National Council are carried out through an electronic voting system. The parliamentary services make all individual votes registered by the system publically available. In contrast, there is no electronic voting system in the Council of States. However, a camera has recorded the Councils' sessions since winter 2006. We have analyzed the video streams and identified individual voting behavior. In a small number of cases, the camera position does not allow identification, but there is no systematic component regarding the decisions and politicians not identified. Our analysis includes all roll call votes on all budgetary referenda since footage from the cameras in the Council's meeting room became available. ${ }^{6}$

\footnotetext{
${ }^{6}$ Note that members of parliament may be absent or abstain from voting due to sickness, travel, political duties, professional bias, or other responsibilities.
} 
We analyze the quality of political representation of the majority of constituents. Democratic decisions are majority decisions and representation of the majority is a natural benchmark case for members of parliament from single and multi-member districts.

Our data on matched Swiss referenda and final votes exhibit several advantages (see Stadelmann et al. (2012b) or Brunner et al. (2011) for a similar discussion on advantages and generalizability). Voters' preferences are measured on precisely the same dimensions as politicians' positions and both cast their votes on exactly the same legislative proposal with identical wording. Information embodied in referenda is much richer than ideology measures. Moreover, preferences are not constructed but observed. Both decisions, i.e. in parliament and in referenda, are real decisions with policy consequences and thus much less superficial than responses given in surveys. In Switzerland, popular votes are also preceded by an intensive public discourse which usually takes 6-8 weeks, or even longer. Therefore, it is fair to say that citizens are much better informed on the respective issues when voting then when answering survey questions. Thus, comparing the roll call votes of legislators with the preferences of the majority of constituents yields a natural and direct measure for congruence, which allows new and interesting insights.

In spite of these advantages, some readers may argue that not all decisions are necessarily presented to voters in a referendum and they may therefore wonder whether the results generalize. We briefly argue why the results are likely to generalize. Firstly, for constitutional amendments, a referendum is always mandatory. Moreover, for law changes, there is a low signature requirement for referenda and less than $1 \%$ of the population is required for a referendum on a parliamentary decision. Subsequently, this ensures that even decisions which are only weakly controversial in parliament may be subject to a referendum. This is because a referendum committee (the group collecting signatures) expects to have a chance to win the majority's support in a referendum or to at least get widespread public attention. By including initiatives which are initiated directly by citizens, we mitigate for selection and agenda setting problems in parliament. Initiatives allow citizens to introduce issues which legislators have neglected and, consequently, lead to better coverage of all policy dimensions relevant for constituents. In addition, the potential threat of a facultative referendum or initiatives gives legislators no systematic incentive to vary their behavior based on whether a referendum will actually occur or not. This is because politicians can never be certain whether their decisions will be challenged by a referendum. Thus, our matches between politicians and citizens do not only cover broad policy issues but are also a representative sample for issues decided in parliament. Finally, Switzerland is not the only country where referenda exist and are important. Brunner et al. (2011) analyze a similar setting as ours for California and suggest generalizability of the central results.

To summarize, our setting and the data allow us to identify empirically whether members of parliament from both chambers diverge from voters' preferences for budgetary decisions and debt increasing/reducing decisions in particular. 


\section{Empirical analysis}

\subsection{Baseline match between constituents and representatives}

In a first step to evaluate the responsiveness of representatives to constituents, we analyze the direct match of representatives' decisions and constituents' decisions. That is, we compare whether representatives decided on legislative proposals in the same way as their constituents. We therefore compare the match between members of parliament and their constituents for all debt increasing and debt reducing referenda. Constituents reveal their preferences only after legislators have voted. Thus, legislators are required to accurately forecast the decisions of their constituents in order to vote in conjunction with their constituencies' preferences which results in a unique measure for divergence as argued by Garrett (1999). ${ }^{7}$ In common with other parliamentary democracies, Swiss legislators also use surveys, elections, personal contacts, etc. to become informed about constituents' preferences.

Each pair of roll call votes and referendum results is analyzed as a single event of either "match/congruence" or "non-match/divergence". For instance, a legislator from the Canton of Zurich who votes "yes" on the budgetary highly relevant "Corporate Tax Reform Act II" matches his constituency's majority opinion and, thus, the preferences of the majority of voters if at least $50 \%$ of voters from the Canton of Zurich also vote "yes" in the referendum. In each case, we present separate results for members of the National Council and members of the Council of States to account directly for differences in the electoral system.

Table 2 presents the congruence between legislators and their constituents. The first column reports the results for members of the National Council and the second column reports results for members of the Council of States.

In $68.6 \%$ of all analyzed legislative and popular decisions with either debt increasing or debt reducing consequences, members of the National Council vote in line with constituents' preferences as shown in column (1), line (a). If the legislative choices of politicians were purely random, i.e. not influenced by constituents' preferences or other factors, we should observe that a politician agrees in half of the cases with the population of his/her electoral district. Put differently, legislators tossing a coin would agree in $50 \%$ of the cases with the majority of their respective districts even if there is no relationship between the politician and the constituency (see Krehbiel 1993 for a similar argument). The $p$ value in parenthesis indicates that matches between representatives and constituents occur significantly more often than in $50 \%$ of all cases. Thus, observed congruence between legislators elected under proportional representation and constituents' preferences is approximately $18.6 \%$ points higher for budgetary referenda than for the purely random choice assumption where members of the Council of States toss a coin.

\footnotetext{
7 Naturally, legislators have to decide first as only then can divergence to voters be measured reasonably. Similarly, in other countries without referenda, surveys on specific laws can only be conducted after laws have been enacted. Otherwise surveys would be of a purely hypothetical nature.
} 
Table 2 Match between politicians and their constituents

(1)

Match between votes of members of teh National Council and the majority of their constituents
(2)

Match between votes of members of the Council of States and the majority of their constituents

\begin{tabular}{lll}
\hline $\begin{array}{l}\text { (a) All referenda } \\
\text { (combined debt }\end{array}$ & $68.55 \%$ & $80.28 \%$ \\
increasing and & $(0.0000)$ & $(0.0000)$ \\
reducing) & & $87.14 \%$ \\
$\begin{array}{l}\text { (b) Debt increasing } \\
\text { referenda }\end{array}$ & $70.35 \%$ & $(0.000)$ \\
(c) Debt reducing & $(0.000)$ & $56.08 \%$ \\
referenda & $56.47 \%$ & $(0.1395)$
\end{tabular}

Values in brackets are $p$ values of the $t$ test testing the average match of the corresponding parliamentarians in the sample against the baseline match of $50 \%$

The comparable congruence is higher for members of the Council of States who are elected under a majority system. In $80.3 \%$ of all legislative decisions affecting the budget, they vote in line with their constituents' preferences as shown in column (2), line (a). Consequently, the observed congruence for members of the Council of States in budgetary decisions is approximately $30.3 \%$ points higher than with the random voting assumption.

Next, we split the referenda analyzed into two distinct groups, i.e. we analyze debt increasing and debt reducing issues separately in lines (b) and (c). Generally, we observe that members of both chambers match constituents' preferences more often in debt increasing than in debt reducing referenda. ${ }^{8}$ For members of the National Council, we observe a congruence of $70.4 \%$ between them and their constituents for debt increasing referenda. The match between members of the National Council and constituents is $56.5 \%$ which is far lower than for debt reducing referenda. Similar results also hold for members of the Council of States. The match between members of the Council of States and constituents is $87.1 \%$ when only debt increasing referenda are analyzed and $56.1 \%$ when focusing on debt reducing referenda.

Thus, this first analysis of the data reveals comparatively higher matches between politicians for debt increasing referenda, while for referenda aiming to decrease debts, we observe low matches. These results do not necessarily imply that politicians try to increase their immediate budgetary leeway as might at first be expected from a strict public choice theory perspective. One has to be careful when interpreting the above congruence results. They only provide a direct interpretation of how politicians represent their constituents for either debt reducing or debt increasing referenda.

\footnotetext{
${ }^{8}$ We focus on the explorative analysis of the data as such a direct comparison of constituents' preferences for debts and legislators' behavior has never been performed before in the literature and existing theory is unclear about the relationship we should observe.
} 


\subsection{Influence of a constituency's preferences on legislators}

In the second step, we estimate a logistical model to explain the "yes-vote" of legislators in both chambers according to whether voters in their electoral district accepted or rejected a referendum. Instead of focusing on the average congruence between voters and legislators under proportional and majority systems, we quantify directly the importance that legislators place on their constituents' preferences for or against debts. We estimate the effect of the predicted majority's "yes-vote" in a referendum on the probability that the legislator will agree on the same issue in parliament. Our explanatory variable is the share of "yes votes" in the canton of the representative which is centered on a tie decision to facilitate interpretation. In other words, the variable CantonYesCentered used in Table 3 takes the number of "yes votes" in a canton minus $50 \%$ such that a value of 0 reflects a perfect tie between supporters and opponents in the district population.

\subsubsection{Interpreting the effects}

We take account of the type of referendum by introducing a separate dummy for debt reducing referenda. Moreover, we account for different voting behavior between the two chambers by splitting the observations into a sample for the National Council and one for the Council of States. We then perform regressions for each of these samples separately.

Results of the logistical model are presented in Table 3. We use district level clustering to correct standard errors which are given in parenthesis. We calculate discrete changes of all variables and report robust standard errors for changes in probability using the Delta method. ${ }^{9}$

Specification (1) shows that the probability of a member of the National Council agreeing to a law proposal affecting public debts increases when the share of "yes votes" by district voters increases. This is reflected by the positive coefficient for the variable CantonYesCentered which indicates that the share of "yes votes" above $50 \%$ has an effect on the probability of the politician voting "yes". We observe that the identifier for debt reducing referenda is significant and negative which indicates that the members of the National Council tend to vote "yes" more often if the legislative proposal aims to increase debt. This result is consistent with the simple public choice argument that the option of debt financing provides present politicians with new resources to target specific interests. This is because it increases the financial leeway of politicians during their relatively short term in office while it narrows the leeway of future politicians during the long term of debt reimbursement. Debt increasing referenda are more likely to increase the leeway of politicians than debt reducing referenda. Nevertheless, in general, politicians seem to place importance on their district voters' preferences for budgetary referenda.

Specification (2) tests whether politicians from the National Council place different importance on the "yes vote" of their constituents in the case of debt

\footnotetext{
9 Ai and Norton (2003) suggest the Delta method to calculate the standard errors of discrete effects for correct estimation.
} 


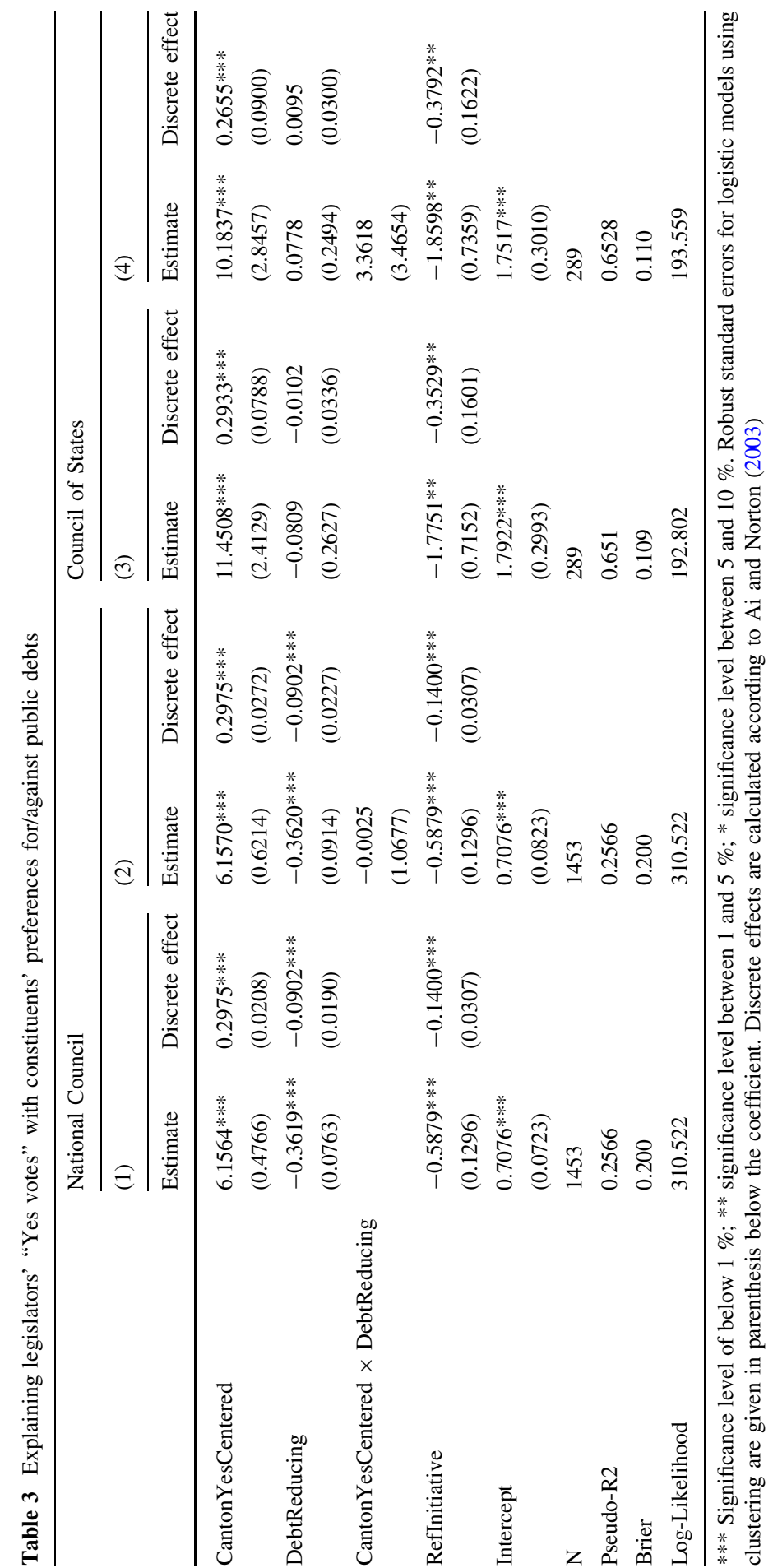


reducing referenda. Therefore, we interact the dummy for debt reducing referenda with the variable CantonYesCentered. The base effect of the influence of constituents' preferences on votes of members of the National Council remains comparable to specification (1). The interaction term is negative, small in size and not significant. Thus, National Councilors do not place a different importance on their constituents for debt reducing than for debt increasing referenda. They only tend to vote "yes" less often for debt reducing referenda, but on average they place the same importance on changes as their constituents for debt reducing and debt increasing referenda.

In general, the match between members of the Council of States and their constituents is higher than the match between members of the National Council and their constituents. We analyze the effect of the variable CantonYesCentered on the probability that a member of the Council of States votes "yes". Similar to before, the effect of the variable CantonYesCentered is positive and highly significant in specification (3). The reaction of members of the Council of States to changes in the "yes vote" of constituents is similar to members of the National Council when calculating the discrete effect for the eight cases of budgetary referenda analyzed here.

In specification (4) we again interact the identifier for debt decreasing referenda with the variable CantonYesCentered. The base effect of the influence of constituents' preferences on votes of the members of the Council of States remains comparable to specification (3). The interaction term is not significant, but it is positive. Thus, members of the Council of States also seem to place the same importance on their constituents in debt reducing and debt increasing referenda. However, they do not have a higher probability to vote "no" for debt reducing referenda as opposed to their colleagues in the National Council who are elected by proportional rule.

\subsubsection{Interpreting the effects}

We interpret the importance that average politicians place on their constituency by predicting the probability that a politician accepts a referendum (voted "yes" in parliament) as a function of the share of constituents accepting the referendum. For all estimates in Table 3 we calculate discrete effects which are presented next to the coefficient estimates. A discrete effect represents the change in the probability of a member of parliament to vote "yes" when the respective independent variable changes while all other variables are evaluated at their median. For the variable CantonYesCentered, we calculate a discrete effect for a change from -0.10 to +0.10 . This corresponds to a shift in the acceptance of a referendum by constituents, from 40 to $60 \%$.

We observe that for budgetary referenda, members of the National Council increase the probability to vote "yes" by $29.8 \%$ points when their constituents agree at a rate of $60 \%$ instead of $40 \%$ as shown by the discrete effect in column (1) of Table 3 next to the coefficient estimate. They are $9.0 \%$ points less likely to accept a debt reducing referendum when all other variables are held at their median and $50 \%$ of the people accept the referendum, i.e. CantonYesCentered equals zero. 
Members of the National Council

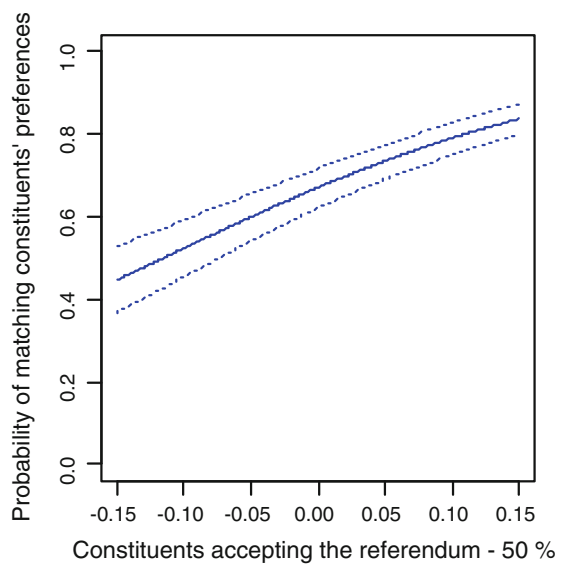

Members of the Council of States

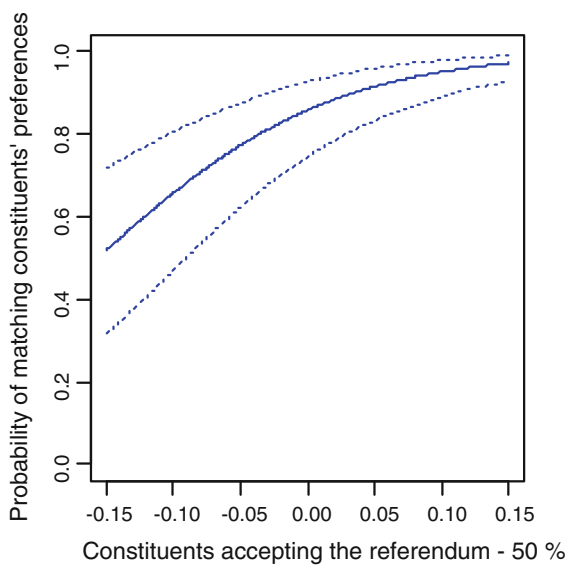

Fig. 1 Probability of representatives to vote as district population. The figure shows the probability that an MP accepts the referendum (voted YES) as a function of his/her share of constituents voting YES from members of the National Council (left panel) and members of the Council of States (right panel). The predictions for the probability are constructed from the results of Table 3, Column (1) and Column (3). The solid line represents the effect of a change in the share of constituents accepting the referendum$50 \%$ (centered at $50 \%$ ) on the probability that an MP accepts the referendum for an average referendum (base effect of CantonYesCentered). The dotted lines give the $95 \%$ confidence interval

Finally, members of the National Council are $14.0 \%$ points more likely to vote against an initiative. All these results remain stable when we interact the variable CantonYesCentered with the identifier for debt reducing referenda.

For members of the Council of States we find that they respond equally to changes in constituents' preferences when compared with members of the National Council. The discrete effect of the variable CantonYesCentered corresponds to $29.3 \%$ points as indicated in column (3) of Table 3 . However, we observe that this effect drops slightly to $26.6 \%$ points because members of the Council of States place slightly more importance on their constituents in the case of debt reducing referenda. ${ }^{10}$

Figure 1 summarizes the main results. We present the importance that legislators place on constituents by varying their support from 35 to $65 \%$, i.e. CantonYesCentered varies from -0.15 to 0.15 . Note that this variation reflects well the actually observed variation in citizens' approval between cantons, i.e. we do not predict out of the sample.

The solid curve represents the effect of a change in the share of constituents accepting the referendum minus $50 \%$ (centered at $50 \%$ ) on the probability that a member of the National Council (left panel) or a member of the Council of States (right panel) accepts the referendum. Thus, the curve represents the base effect of the variable CantonYesCentered which is equal to zero when exactly $50 \%$ of constituents agree to the referendum.

\footnotetext{
${ }^{10}$ Although the interaction term has no significant effect, its inclusion reduces the predicted discrete effect for the variable CantonYesCentered.
} 
We observe that politicians from both chambers place importance on their constituents in the case of those referenda which affect public debts. ${ }^{11}$ If the support of constituents for a referendum affecting public debts in either way increases then politicians are more likely to vote "yes" too. Members of the Council of States place a slightly higher importance on their constituents when constituents' support is fairly low. That is, the curve for members of the Council of States is slightly steeper and starts at a higher level of congruence than it does for members of the National Council. In general, the reaction of the two groups of politicians to constituents' preferences over the analyzed spectrum is similar but the additional importance members of the Council of States place on constituents ebbs out at a high level.

\section{Conclusion}

Political representation concerns the correspondence between legislators' behavior and the will of constituents. The behavior of politicians towards their constituents is particularly important for political decisions affecting public debts. This paper fills an important gap in the literature by directly considering congruence between the preferences of the majority of constituents and legislators for public debt decisions. Under an institutional setting comparable to some US states and other jurisdictions using direct democratic instruments, we use quasi-experimental data and match revealed citizens' preferences with legislators' roll call votes in parliament. Constituents regularly reveal their preferences in popular referenda in Switzerland. Representatives to the Swiss National Council and the Swiss Council of States vote on exactly the same legislative proposals with identical wording as people vote on in referenda. We identify those referenda potentially affecting public debts and analyze how legislators represent their constituents' preferences for debt increasing and debt reducing proposals.

Our empirical results suggest that legislators of both chambers deviate in decisions concerning public debts from the preferences of the majority of their constituents. Members of the National Council who are elected under proportional representation vote on average $18.6 \%$ points more with their constituents in budgetary decisions than a purely random model of politicians flipping a coin would predict. The respective match is higher for members of the Council of States who are elected under majority voting. Politicians of both chambers match the majority of their constituents at a lower level for debt reducing than for debt increasing referenda. However, additional results show that they place approximately the same importance on changes in constituents' preferences for both types of referenda. Finally, we find that politicians elected under proportional rule tend to vote more in favor for debt increasing proposals while there is no significant difference for members of the Council of States elected by majoritarian rule for debt increasing or debt reducing proposals.

\footnotetext{
11 Note that from the estimates we know that they place approximately the same importance on constituents' preferences for debt reducing as well as debt increasing referenda.
} 
When interpreting these direct empirical results, they first may seem to be at odds with the view that politicians tend to increase public debts while citizens tend to reduce them. We only find a certain tendency for politicians elected by proportional rule to vote for increasing debts but the importance they place on changes in their constituents' preferences is not affected by this behavior. However, as the match with preferences of constituents in general is fairly low, we may speculate that politicians try to maximize their own utility function. ${ }^{12}$ Our results indicate that politicians are not necessarily interested in simply increasing their budgetary leeway by going for higher debts. Instead, they may tend to have more specific and more individual goals than a simple theory of increasing public debts for personal leeway would predict.

We aim to conduct further analyses to test these hypotheses. We are collecting information on representatives' interest affiliations and their professions. These data should permit us in the future to estimate the joint influence of legislators' personal characteristics combined with the task of representing constituents' preferences in real legislative decisions affecting public debts. Moreover, an interesting field of research for the future would be to focus on the competing influence of voters and interest groups when analyzing politicians' decisions.

Acknowledgments We are grateful to Geoffrey Brennan, Giuseppe Eusepi, Lars Feld, Bernard Grofman, Richard E. Wagner, Stanley L. Winer, the participants of the conference of the European Center for the Study of Public Choice, 2011 in Rome and the 2012 Annual Meeting of the Public Choice Society for illuminating and inspiring discussions. Especially, we would like to thank Ann Barbara Bauer for supporting us with the identification of political decisions affecting public debts.

\section{References}

Ågren, H., Dahlberg, M., \& Mörk, E. (2007). Do politicians' preferences correspond to those of the voters? An investigation of political representation. Public Choice, 130(1/2), 137-162.

Ai, C., \& Norton, E. C. (2003). Interaction terms in logit and probit models. Economics Letters, 80(1), $123-129$.

Alesina, A., \& Drazen, A. (1991). Why are stabilizations delayed? American Economic Review, 81(5), 1170-1188.

Alesina, A., \& Rosenthal, H. (1989). Partisan cycles in congressional elections and the macroeconomy. American Political Science Review, 83(2), 373-398.

Bender, B., \& Lott, J. R. (1996). Legislator voting and shirking: A critical review of the literature. Public Choice, 87(1-2), 67-100.

Besley, T., \& Coate, S. (2008). Issue unbundling via citizens' initiatives. Quarterly Journal of Political Science, 3(4), 379-397.

Brennan, G. (2011). The political economy of public debt. Mimeo. Duke University \& Australian National University.

Brunner, E. J.; Ross, S. L. \& Washington, E. L. (2011). Does less income mean less representation? Technical report, National Bureau of Economic Research, Inc, NBER Working Papers, WP No. 16835.

Carey, J. M. (2007). Competing principals political institutions, and party unity in legislative voting. American Journal of Political Science, 51, 92-107.

\footnotetext{
${ }^{12}$ Anecdotal evidence suggests that many representatives are entrepreneurs and almost all representatives have certain interest affiliations with private companies. This might be a possible explanation why a referendum such as the "Corporate Tax Reform Act II" aiming at reducing taxes for private companies passed the parliament although tax reductions reduce politicians budgetary leeway in the short run.
} 
Denzau, A. T., \& Munger, M. C. (1986). Legislators and interest groups: How unorganized interests get represented. The American Political Science Review, 80(1), 89-106.

Dow, J. K. (2001). A comparative spatial analysis of majoritarian and proportional elections. Electoral Studies, 20(1), 109-125.

Downs, A. (1957). An economic theory of democracy. New York: Harper \& Row.

Drazen, A., \& Grilli, V. (1993). The benefit of crises for economic reforms. American Economic Review, 83(3), 598-607.

Eusepi, G., \& Wagner, R. E. (2012). Indebted state versus intermediary state: Who owes what to whom? Mimeo. George Mason University.

Feld, L. P., \& Matsusaka, J. G. (2003). Budget referendums and government spending: Evidence from Swiss cantons. Journal of Public Economics, 87(12), 2703-2724.

Frey, B. S. (1994). Direct democracy: Politico-economic lessons from swiss experience. American Economic Review, 84(2), 338-342.

Garrett, T. A. (1999). A test of shirking under legislative and citizen vote: The case of state lottery adoption. Journal of Law and Economics, 42(1), 189-208.

Gerber, E. R. (1996). Legislative response to the threat of popular initiatives. American Journal of Political Science, 40(1), 99-128.

Gerber, E. R., \& Lewis, J. B. (2004). Beyond the median: Voter preferences district heterogeneity, and political representation. Journal of Political Economy, 112(6), 1364-1383.

Golder, M., \& Stramski, J. (2010). Ideological congruence and electoral institutions. American Journal of Political Science, 54(1), 90-106.

Grofman, B. (2004). Downs and two-party convergence. Annual Review of Political Science, 7, 25-46.

Hersch, P. L., \& McDougall, G. S. (1988). Voting for 'sin' in Kansas. Public Choice, 57(2), 127-139.

Kau, J. B., \& Rubin, P. H. (1978). Voting on minimum wages: A time-series analysis. Journal of Political Economy, 86(2), 337-342.

Kau, J. B., \& Rubin, P. H. (1979). Self-interest ideology, and logrolling in congressional voting. Journal of Law and Economics, 22(2), 365-384.

Kenny, L., \& Lotfinia, B. (2005). Evidence on the importance of spatial voting models in presidential nominations and elections. Public Choice, 123(3), 439-462.

Krehbiel, K. (1993). Constituency characteristics and legislative preferences. Public Choice, 76(1-2), 21-37.

Levitt, S. D. (1996). How do senators vote? Disentangling the role of voter preferences, party affiliation, and senator ideology. The American Economic Review, 86(3), 425-441.

López, E., \& Ramírez, C. (2008). Mr. Smith and the economy: The influence of economic conditions on individual legislator voting. Public Choice, 136(1), 1-17.

Lott, J. R., \& Davis, M. L. (1992). A critical review and an extension of the political shirking literature. Public Choice, 74(4), 461-484.

Matsusaka, J. G. (1995). Fiscal effects of the voter initiative: Evidence from the last 30 years. Journal of Political Economy, 103(3), 587-623.

Matsusaka, J. G. (2010). Popular control of public policy: A quantitative approach. Quarterly Journal of Political Science, 5(2), 133-167.

Portmann, M., Stadelmann, D., \& Eichenberger, R. (2012). District magnitude and representation of the majority's preferences: Quasi-experimental evidence from popular and parliamentary votes. Public Choice, 151(3-4), 585-610.

Schneider, F., Pommerehne, W. W., \& Frey, B. S. (1981). Politico-economic interdependence in a direct democracy: The case of Switzerland. In Douglas A. Hibbs \& Heino Fassbender (Eds.), Contemporary political economy, studies on the interdependence of politics and economics. Amsterdam: North Holland.

Stadelmann, D., Portmann, M., \& Eichenberger, R. (2012a). Evaluating the median voter model's explanatory power. Economics Letters, 114(3), 312-314.

Stadelmann, D., Portmann, M., \& Eichenberger, R. (2012b). Quantifying parliamentary representation of constituents' preferences with quasi-experimental data. Journal of Comparative Economics (forthcoming).

Stratmann, T. (1992). Are contributors rational? Untangling strategies of political action committees. The Journal of Political Economy, 100(3), 647-664.

Stratmann, T. (1995). Campaign contributions and congressional voting: does the timing of contributions matter? Review of Economics and Statistics, 77(1), 127-136. 